\title{
The Origins, Development and Evaluation of Mathematics Support Services
}

\author{
OLIVIA GILL, CIARÁN MAC AN BHAIRD, AND EABHNAT NÍ FHLOINN
}

\begin{abstract}
This article is an introductory overview of the recent expansion in the development and provision of mathematics support services at third level. In the last ten years the establishment of Mathematics Support and Learning Centres has increased significantly in Ireland and the UK. Most third level institutes in Ireland now supply some level of mathematics support. We will discuss the development of these supports as well as the reasons why third level institutes have decided to introduce them. We also give an overview of how these services are evaluated and the impact that they appear to have on student retention and performance.
\end{abstract}

\section{INTRODUCTION}

There is widespread concern about the number of students entering who have basic mathematical problems. Recent reports, (Hourigan \& ODonoghue, 2007; Lynch et al., 2003), contain detailed analysis of these issues in the teaching and learning of mathematics at second level in Ireland. Some of the main factors listed include: bad publicity for mathematics, negative attitudes towards the subject, little understanding of the context or background of mathematics and rote learning. The National Council for Curriculum and Assessment review (NCCA, 2005) and Cosgrove et al. (2004) have highlighted possible impacts of these problems. The Organisation for Economic Co-operation and Development report (1999) discusses the impact that this has when these students enter third level. Low attainment in mathematics is cited as a contributing factor in low enrolment and retention rates in science and technology courses (OECD, 1999; IDES 2002). There is also significant international research on these issues (Picker \& Berry, 2001). 
The provision of mathematics support is one response from third level institutions to try and address these issues. The main aim is to assist students in overcoming their mathematical difficulties. Mathematics support is also active in helping students with different challenges and backgrounds such as Access, Disability and Mature students. It aims to provide a better mathematics learning experience for students from all these backgrounds. Organisations such as NCE-MSTL (The National Centre for Excellence in Mathematics and Science Teaching and Learning) based in the University of Limerick and sigma (The Centre of Excellence in Mathematics and Statistics Support) based in the UK have been established to promote and expand, amongst other things, the area of mathematics support. sigma, for example, has helped establish mathematics support networks (hubs) in various parts of the UK. The Irish Mathematics Support Network (IMSN) was also established in 2009 to promote mathematics support on a national basis.

In this paper we will present an overview of the creation and subsequent development of mathematics support and learning services. We will review the reasons why such supports have been established, their rapid development over the past decade and the evaluations that are carried out on these services. To some extent, this paper is an introductory literature review of the research carried out in these areas.

\section{Why are additional Maths Support Services Being PROVIDED?}

The poor core mathematical skills of a large number of students entering third-level education has been a growing cause for concern for mathematics educators for many years now. This concern has been expressed in numerous journal articles and conference proceedings, and inquiries have been undertaken to ascertain the mathematical accomplishment of these students.

In Ireland, studies were being undertaken as early as 1985. A paper from Cork Regional Technical College (now Cork Institute of Technology (CIT)) in 1985 concluded that their incoming undergraduates were deficient in basic mathematics. Similar findings were reported in University College Cork (Hurley \& Stynes, 1986), and a number of other universities and institutes soon followed suit (Brennan, 1997; O'Donoghue,1999). In Hourigan \& O'Donoghue (2007), 
the authors discuss some of the details of the problems that are apparent at third-level. They state (p.461) "the inability of students to successfully make the transition to tertiary level mathematics education lies in the substantial mismatch between the nature of entrants pre-tertiary mathematical experiences and subsequent tertiary level mathematics-intensive courses." Indeed, the "mathematics problem" at all levels in Ireland has received considerable focus of late, with a comprehensive review of post-primary mathematics education in Ireland (NCCA, 2005) and internationally (Conway \& Sloane, 2005) undertaken by the National Council for Curriculum and Assessment (NCCA) leading to the introduction of the new Project Maths syllabus this year.

In the UK, in 1995, the London Mathematical Society (LMS), the Institute of Mathematics and its Applications (IMA) and the Royal Statistical Society (RSS) produced their report Tackling the Mathematics Problem. They investigated concerns amongst mathematicians, scientists and engineers in Higher Education about the mathematical preparedness of new undergraduates. In the same year, the Engineering Council also commissioned a report to investigate anecdotal evidence and growing speculation that the mathematical background of undergraduate engineers had changed. The findings showed that, amongst this body of students, mathematical knowledge was weaker than it had been ten years previously (Sutherland \& Pozzi, 1995). On a wider scale, the Gatsby Charitable Foundation sponsored a seminar to investigate the same issue in departments of Mathematics, Physics and Engineering. Again, the findings showed strong evidence of a steady decline in basic mathematical skills and increasing inhomogeneity in mathematical attainment and knowledge (Savage et al., 2000). There has, subsequently, been a number of government-funded inquiries, for example, Inquiry Into A Level Standards (Tomlinson, 2002), SET for success (Roberts, 2002) and Making Mathematics Count (Smith, 2004) investigating the standards, suitability and uptake of pre-19 mathematics qualifications.

These issues are not exclusive to Ireland and the United Kingdom; reports of this kind have been produced worldwide. Eight years ago, when the Mathematics Working Group for the European Society for Engineering Education (SEFI-MWG) produced the first revision to their report on a mathematics curriculum for engineers, they noted that "In increasingly more countries, there is concern over the deterioration in the mathematical ability of new entrants to engineering 
degree programmes." (SEFI, 2002). In Australia, a government report on teaching produced by McInnes \& James (1995) focused on the experiences of first-year undergraduate students. It "identified weaknesses in mathematical skills and confidence as a barrier for success for many students." (MacGillivray, 2008).

These reports give credibility to the fact that real difficulties are being experienced by both students and staff in numerate disciplines. Added to this perceived decline in knowledge, a shift in effort and student attitude was reported by the SEC (2001), with evidence of a distinct lack of perseverance in the answering of questions in the Leaving Certificate examination. Even higher level students were a cause of unease, which is similar to findings reported in the UK (LMS, 1995). A lack of competence in mathematics is problematic as it can lead to: "Stunted advancement in other areas of the degree programmes... Compromised standard of degrees... Amplified failure rates and deflated self esteem.." (O'Donoghue, 1999). These mathematical deficiencies need to be addressed as early as possible in students' university lives.

\section{The Growth and Expansion of Mathematics Support SERVICES}

To determine the extent of the "mathematics problem", diagnostic testing has been carried out across Irish third level institutions since the 1980s. In a study carried out in the University of Limerick (UL) in 1997 (O'Donoghue, 1999), it was revealed that $30 \%$ of first year service mathematics undergraduates were mathematically underprepared for the demands of their service mathematics modules. While the support tutorials which were initially provided indicated improvements in student performance in general, the need for a one-to-one approach was becoming more critical.

In October 2001, Ireland's first Mathematics Learning Centre opened in UL. The Centre, which was based on the model of the Loughborough University support centre

$$
\text { http://www .mathcentre.ac.uk/ }
$$

continues to carry out diagnostic testing and uses the results to diagnose and support students, as well as for research purposes. The need for similar type centres was recognised across all higher education institutions and most have followed suit. 
The Learner Support Unit at Mary Immaculate College of Education was established in 1997 to deliver academic support to degree level students. Mathematics support provision was first provided by the unit in 2002/03. Also, in 2002, Dublin Institute of Technology opened their Students' Maths Learning Centre for all students participating in service mathematics modules. In 2003, the Department of Computing and Networking in IT Carlow received funding from the "Information Technology Investment Fund" to set up a "drop-in" centre to help first year students in programming and mathematics, the two most problematic subjects. While mathematics support was on-going in Tallaght Institute of Technology in the 1990s, in 2003 the Engineering Learning Support Unit was formally established. This centre was also based on a model inspired by mathematics learning support in Loughborough University. One of its aims was to provide mathematics help to engineering students. In January 2005, this facility was renamed the Learning Support Unit. Also in 2003, the Department of Mathematics in University College Dublin (UCD) received Higher Education Authority funding to set up the UCD Mathematics Support Centre which formally opened on 16th February 2004.

The Maths Learning Centre in Dublin City University (DCU) originally took the form of Maths Clinics, scheduled two evenings a week for first year students between 2001 and 2003. The Maths Learning Centre then opened in February 2004 and was established as a permanent entity (funded by the Faculty of Science and Health) in September 2007. Limerick Institute of Technology also launched its Learning Support Unit in March 2004. The Mathematics Support Centre (MSC) in the National University of Ireland Maynooth (NUIM) started on a small scale initially in 2004/2005. It opened on a larger basis in September 2007 and has grown significantly since due to student demand. CIT followed closely behind, opening their Learning Support Centre in September 2005 with a mission to support students predominantly in Mathematics, Physics, Programming and Electronics. The Mathematics Learning Centre in Letterkenny Institute of Technology was formally established in 2006.

In 2001, a total of 95 Higher Education Institutions in the U.K. were surveyed to investigate the extent to which mathematics support was being offered. 46 stated that they offered support over and above traditional lectures and tutorials (Lawson et al., 2001). In 2004 , a survey uncovered that $62.3 \%$ of 106 U.K. universities stated 
that they were providing some form of mathematics support (Perkin $\&$ Croft, 2004). This represents a $14 \%$ increase in supports being offered over a 3 year period.

Gill et al. (2008) carried out an audit of Mathematics Learning Support in 13 Irish third level institutions in 2008, many of the findings are detailed above. Institutes who at the time of writing had no formal physical presence in terms of a drop-in centre were on the path to doing so and were providing mathematics support in the form of support tutorials and online support. Therefore, it is reasonable to assume that not only are more Higher Education institutions in Ireland offering support than those detailed above, but there has been an increase in the number of facilities being provided. Participants at the 4th Irish Workshop on Maths Learning and Support Centres at DCU reported on many of these supports, especially from a technological point of view. Ní Fhloinn (2010a) contains an overview of this conference.

\section{The Evaluation of Maths Support Services.}

Continuous and thorough evaluations of mathematics support services is of critical importance to the establishment of best practice and the maintenance of these services for the students who need them. In the previous sections, many of the reasons behind the widespread establishment and development of support services has been documented. In this section we look at how these services are evaluated nationally and internationally and how this research impacts on the services provided and the establishment of new initiatives. Lawson et al. (2001 and 2002) give excellent introductory articles on what the first steps of evaluation should be.

The most basic level of evaluation are the levels of engagement or attendance figures at the various supports. Most of the services in Ireland do not have permanent funding, so the maintenance and analysis of these records is critical. It is both beneficial for the institution to see the overall levels of engagement, and also for students to observe that their peers are engaging with these services. The figures are also vital for the service administrators as they can indicate the need for additional staff and supports to deal effectively with students. This data is recorded in most third level institutes and copies of the annual audits are available upon request. The importance of 
maintaining these records is evident from the case of a mathematics support service in Wales. Until recently, they did not maintain concise and accurate records. They wanted to keep the support as informal as possible to encourage more students to attend. However, when their institution conducted an annual review of the service, it was almost shut down as there was very little evidence (other than anecdotal) of the numbers attending or the impact of their service. This centre now maintains a complete and thorough record of usage.

Clearly the number of users of mathematics support services does not necessarily measure the impact of the supports offered. An initial step is to consider the impact that services appear to have on students' grades and retention rates. It should also be noted at this stage that it is difficult to evaluate the performance of the services using students' mathematics grades alone because so many factors affect performance on examinations. It is impossible to measure how much time students spend studying the subject. It is possible that students who attend the services do better in their exams than those who do not simply because these students worked harder. With this in mind, many studies also consider performance on past examinations when comparing the grades of the students who attend the services with those who do not attend.

A number of studies have been carried out at Irish Universities. Gill \& O'Donoghue (2007) look at various ways of measuring the success of the support service provided by a mathematics learning centre. Dowling \& Nolan (2006) looked at the pass rates of at-risk students at DCU, and concluded that their Mathematics Learning Centre (MLC) made a positive contribution to student retention. Ní Fhloinn (2010b) looked at the role of student feedback in evaluation the effectivenss of DCU MLC, merging qualitative and quantitative data. Mac an Bhaird et al. (2009) discussed the impact of the Maths Support Centre (MSC) on the grades of first year students at NUIM. It appeared to have an impact on the majority of students who attended regularly, especially the most at-risk students. The importance of effectively evaluating such services in Ireland was highlighted by the 3rd Irish Workshop on Maths Learning and Support Centres held at NUIM in December 2008. The conference theme was Is Mathematics Support worthwhile? The speakers presented on the broad range of the various services provided in Ireland and the evaluations that are carried out. An overview is available in Mac an Bhaird \& O'Shea (2009). 
In the UK, where mathematics support has a slightly longer history, more detailed evaluations have been carried out. Pell \& Croft (2008) consider first year Engineering students at Loughborough University. They estimated that attending the Mathematics Support Centre improved the pass rate of students by about $3 \%$. Patel \& Little (2006) had similar findings. Lee et al. (2008) used regression models and found that the results of diagnostic tests and attendance at Mathematics Support Centres were significant predictors of end of year results. Parsons (2005) describes how introducing mathematics support and implementing other changes has had a positive effect on engineering maths students. There are a number of studies in other countries also. Terlouw et al. (2008) report on the success of a special mathematics course designed to help the transition from second to third level in the Netherlands. MacGillivray \& Cuthbert (2007) report on the initiatives introduced to help engineering students in Australia and the found that students who avail of supports are nearly twice as likely to complete the course and half as likely to discontinue with engineering.

One of the main developments from these initial studies are questions regarding the type of student who avails of mathematics support; whether or not support is reaching its target group; and why certain students do not avail of support. The benefits of mathematics support to students with weak mathematical backgrounds is well documented in Patel \& Little (2006), Dowling \& Nolan (2006), Lee et al. (2008) and Mac an Bhaird et al. (2009) for example. Patel (2004) reports on a study which identifies the effectiveness of combining appropriate mathematical diagnosis with study support. Croft \& Grove (2006) look at the type of students who avail of support. In addition, some authors have been able to report on the use of support services by students with strong mathematical backgrounds. Pell \& Croft (2008) consider the number of times first-year Engineering students attend the Mathematics Support Centre in Loughborough University and the grade they receive on their mathematics modules. They found that students who received the top grades were more likely to attend than those who failed or who just passed the module. They comment that the provision of mathematics support has moved from a remedial measure to one of enhancement for the whole student cohort. Similar results have been reported by MacGillivray (2009). She 
considered the attendance patterns of students, and found that engineering students at the Queensland University of Technology across all abilities make good use of the support services on offer there.

While the majority of research provides evidence that these supports are successful, there is also evidence that not all students are engaging; in particular it should be noted that a significant minority of at-risk students are neither availing of support nor engaging with mathematics. Some authors have found that the fear of showing a lack of knowledge or ability negatively impacts on students' willingness to ask questions (Ryan et al., 2001). Grehan et al. (2010) focuses on the fears that students expressed and how these fears prevented them from engaging with mathematics during their first year at university. This fear manifested itself in four different ways: fear of failure; fear of showing a lack of knowledge or ability; fear of being singled out; and fear of the unknown. Students also displayed a lack of awareness of services or structures within mathematics. Many of these factors were also identified in a study of students at Loughborough University (Symonds et al., 2008).

The process of evaluating mathematics support initiatives is clearly an important and very complex issue. MacGillivray \& Croft (2010) contains a thorough and conclusive overview and analysis of the issues at hand. The Irish Mathematics Support Network will issue a national questionnaire for support service users in the coming months, so the impact of services on a national scale can be collated and analysed. The evaluation of services and the impact on students, why they attend or do not attend clearly has very important implications. It allows the centres to develop best practice and also allows us to investigate what students really want from the service we provide.

\section{Conclusions.}

The area of mathematics support services is clearly crucial to mathematics education at third level, especially considering the large numbers of students who are taking service mathematics as part of their degree. We have given some background and evidence of the "mathematics problem" and the issue it raises at third level. We have talked about the development of mathematics learning and support services as a response to these issues and we have presented research which suggests that students who avail of these supports tend to perform 
better. However, research also indicates that there are more complex issues involved and further investigations are required.

\section{REFERENCES}

[1] Brennan, M. (1997) The 2nd-3rd level mathematics interface. In Cawley, S., (Ed.), A Mathematics Review, pp. 3-15, Dublin: Blackhall Publishing.

[2] Conway, P. \& Sloane, F. (2005) International Trends in Post-Primary Mathematics Education. National Council for Curriculum and Assessment, http://www.ncca.ie/uploadedfiles/Publications/MathsResearch.pdf (09/11/10)

[3] Department of Mathematics and Computing. (1985) Report on the basic mathematical skills test of 1st year students in Cork R.T.C. in 1984. I.M.S. Newsletter, Vol. 14, pp 33-43.

[4] Cosgrove, J., Shiel G., Oldham, E. \& Sofroniou, N. (2004) A survey of Mathematics teachers in Ireland. The Irish Journal of Education, Vol. 35, pp 20-44.

[5] Croft, A. C. \& Grove, M. (2006) Mathematics Support: Support for the specialist mathematician and the more able student. MSOR Connections, Vol. 6, pp 39-43.

[6] Dowling, D. \& Nolan, B. (2006) Measuring the effectiveness of a maths learning centre The Dublin City University experience. Proceedings of the CETL MSOR Conference 2006, pp 51-54.

[7] Gill, O., Johnson, P. \& O'Donoghue, J. (2008) An Audit of Mathematics Support in Irish Third Level Institutions. CEMTL: University of Limerick.

[8] Gill, O. \& O'Donoghue, J. (2007) Justifying the existence of Mathematics learning support: Measuring the effectiveness of a mathematics learning centre. Proceedings of the ALM, Vol. 14. http://www.mathcentre.ac.uk/resources/uploaded/alm14olivia.pdf (09/11/10)

[9] Hurley, D. \& Stynes, M. (1986) Basic mathematical skills of U.C.C. students. I.M.T.A. Bulletin, Vol. 17, pp 68-79.

[10] London Mathematics Society. (1995) Tackling the Mathematics Problem. Southend-on-Sea: L.M.S.

[11] Grehan, M., Mac an Bhaird, C. \& O'Shea, A. (2010) Why do students not avail of mathematics support? A case study of first year students at the National University of Ireland Maynooth. Proceedings of the British Congress of Mathematics Education 2010, pp 254-258.

[12] Hourigan, M. \& O'Donoghue, J. (2007) Mathematical under-preparedness: the influence of the pre-tertiary mathematics experience on students ability to make a successful transition to tertiary level mathematics courses in Ireland. International Journal of Mathematical Education in Science and Technology, Vol. 38, 4, pp 461-476.

[13] Irish Department of Education and Science (IDES) (2002). Task Force on the Physical Sciences, Report and Recommendations. Dublin, Government Stationary Office.

[14] Lawson, D. A., Halpin, M. \& Croft, A. C. (2001) After the diagnostic test - what next? Evaluating and enhancing the effectiveness of mathematics support centres. MSOR Connections Vol. 1, pp 19-23. 
[15] Lawson, D. A., Halpin, M. \& Croft, A. C. (2002) After the diagnostic test - what next? Evaluating and enhancing the effectiveness of mathematics support centres - Part 2. MSOR Connections Vol. 2, pp 23-26.

[16] Lee, S., Harrison, M., Pell, P. \& Robinson, C. (2008) Predicting performance of first year engineering students and the importance of assessment tools therein. Engineering Education, Vol. 3, pp 44-51.

[17] LMS, IMA \& RSS. (1995) Tackling the Mathematics Problem. London Mathematical Society, London, UK.

[18] Lynch, K., Lyons, M., Sheerin, E., Close, S. \& Boland, P. (2003) Inside Classrooms: a Study of Teaching and Learning. Dublin: Institute of Public Administration.

[19] Mac an Bhaird, C., Morgan, T. \& O'Shea, A. (2009) The Impact of the Mathematics Support Centre on the Grades of First Year Students at the National University of Ireland Maynooth. Teaching Mathematics and its Applications, Vol. 28, 3, pp 117-122.

[20] Mac an Bhaird, C. and O'Shea, A. (2009) Is Mathematics Support worthwhile? An overview of the 3rd Irish Workshop on Mathematics Learning and Support Centres. MSOR Connections, Vol. 9, 2, pp 52-59.

[21] MacGillivray, H. (2008). Learning Support in Mathematics and Statistics in Australian Universities: A guide for the university sector. Australian Teaching and Learning Council. http://www. altc. edu. au/resource-learning-support-mathematics-guide-qut-2008 $(09 / 11 / 10)$

[22] MacGillivray, H. (2009) Learning support and students studying mathematics and statistics. International Journal of Mathematics Education in Science and Technology, Vol. 40, pp 455-472.

[23] MacGillivray, H. \& Cuthbert, R. (2007) Investigation of completion rates of engineering students. Proceedings of the Southern Hemisphere Symposium on Undergraduate Mathematics Teaching (Delta). http://www.mathcentre.ac.uk/resources/uploaded/delta-2007-cuthbert -macgillivray.pdf International $(11 / 11 / 10)$

[24] MacGillivray, H. \& Croft, A. C. (2010) Understanding evaluation of learning support in mathematics and statistics. International Journal of Mathematical Education in Science and Technology, pp 1-24. http://pdfserve. informaworld.com/481740_751307824_929079762.pdf (11/11/10)

[25] McInnes, C. \& James, R. (1995) First year on campus: Diversity in the Initial Experiences of Australian Undergraduates. AGPS, Canberra, Australia.

[26] National Council for Curriculum and Assessment (NCCA) (2005) Review of Mathematics in postprimary education (a discussion paper). Dublin, NCCA. http://www.ncca.ie/uploadedfiles/MathsReview/MathsDiscusPaperEng.pdf $(09 / 11 / 10)$

[27] Organisation for Economic Co-operation and Development (OECD) (1999)Measuring student knowledge and skills: A new framework for assessment. Paris, OECD. 
[28] O'Donoghue, J. (1999) An intervention to assist at risk students in service mathematics courses at the University of Limerick. University of Limerick teaching fellowship scheme, University of Limerick, Limerick.

[29] Parsons, S. (2005) Success in engineering mathematics through mathematics support and changes to engineering maths lectures at Harper Adams. MSOR Connections, Vol. 5, 1, pp 1-4.

[30] Patel, C. (2004) Participation (Diagnosis + Prescription) $=$ Resolution. MSOR Connections, Vol. 4, No. 2, pp 19-21.

[31] Patel, C. \& Little, J. (2006) Measuring maths study support. Teaching Mathematics and its Applications, Vol. 25, 3, pp 131-138.

[32] Pell, G. \& Croft, T. (2008) Mathematics support support for all?. Teaching Mathematics and its Applications, Vol. 27, pp 167-173.

[33] Perkin G. \& Croft, A. C. (2004) Mathematics Support Centres - the extent of current provision. MSOR Connections Vol. 4, pp 14-18.

[34] Picker, S.H. \& Berry, J.S. (2001) Investigating pupils images of mathematics. Proceedings of the 25th Conference of the International Group for the Psychology of Mathematics Education, Vol. 4, pp 49-56.

[35] Roberts, G. (2002) SET for success: the supply of people with science, technology, engineering and mathematics skills. The Report of Sir Roberts Review. Accessed via http://webarchive.nationalarchives.gov.uk/+/http://www.hm-treasury.gov.uk/ documents/enterprise_and_productivity/research_and_enterprise/ent_ res_roberts.cfm $(09 / 11 / 10)$.

[36] Ryan, A.M., Pintrich, P. R. \& Midgley, C. (2001) Avoiding seeking help in the classroom: Who and why? Educational Psychological Review, Vol. 13, No. 2, pp 93-114.

[37] Savage, M., Kitchen, A., Sutherland, R. \& Porkess, R. (2000) In Hawkes, T. \& Savage, S. (Eds). (2000). Measuring the Mathematics Problem. The Engineering Council, London, UK.

[38] State Examinations Commission. (2001) Leaving certificate examination 2001 mathematics chief examiner's report for higher, ordinary and foundation levels. Department of Education and Science, Dublin. http://www. examinations.ie/archive/examiners_reports/cer_2001/ lcmaths_ol_01_er.pdf $(10 / 11 / 10)$

[39] European Society for Engineering Education (SEFI) (2002). In Mustoe, L. \& Lawson. D. (Eds) First Revision of Report by the SEFI Mathematics Working Group Mathematics for the European Engineer: A Curriculum for the Twenty-First Century. http://sefi.htw-aalen.de/ (09/11/10)

[40] Smith, A. (2004) Making Mathematics Count. The report of Professor Adrian Smiths Inquiry into Post-14 Mathematics Education. The Stationery Office, London, UK.

[41] Sutherland, R. \& Pozzi, S. (1995) The Changing Mathematical Background of Undergraduate Engineers: a review of the issues. The Engineering Council, London, UK.

[42] Symonds, R., Lawson, D. \& Robinson, C. (2008) Promoting student engagement with mathematics support. Teaching Mathematics and its Applications, Vol. 27, 3, pp 140-149. 
[43] Terlouw, C., de Goede, R. \& Kienhuis, M. (2008) The effectiveness of a special mathematics course for improving the transition from secondary eduction to higher professional education. Proceedings of the 7 th International conference of The London Scholarship of Teaching and Learning, Vol. 4, pp 58-68.

[44] Tomlinson, M. (2002) Inquiry into A Level Standards.

Olivia Gill,

Department of Mathematics, University of Limerick, Limerick, Ireland olivia.gill@ul.ie

Eabhnat Ní Fhloinn,

School of Mathematical Sciences, Dublin City University,

Glasnevin, Dublin 9, Ireland eabhnat.nifhloinn@dcu.ie
Ciarán Mac an Bhaird,

Department of Mathematics,

National University of Ireland, Maynooth, Ireland

ciaran.macanbhaird@maths.nuim.ie

Received on 15 November 2010. 